\title{
Aerosol concentration and fetch
}

\author{
Jacques Piazzola ${ }^{a}$, Alexander M.J. Van Eijk ${ }^{b}$, and Gerrit de Leeuw ${ }^{b}$ \\ ${ }^{a}$ LEPI, University of Toulon-Var, France \\ ${ }^{\mathrm{b}}$ Physics and Electronics Laboratory, TNO, The Hague, The Netherlands
}

\begin{abstract}
On the basis of a comprehensive series of measurements on the Irish Atlantic coast, an extension of the Navy Aerosol Model (NAM) for the coastal zone is proposed. As in NAM, the dependence of the aerosol concentration on meteorological parameters is parameterized using empirical coefficients. The effect of continental aerosols present in the coastal zone is modeled as a function of fetch. A reasonable agreement is found between the model and the acrosol size distributions as measured on the island Inisheer.
\end{abstract}

Keywords: coastal aerosols; optical propagation: NAM; fetch

\section{INTRODUCTION}

The assessment of electro-optical (EO) systems with propagation prediction codes requires accurate atmospheric models. In particular. the performance of EO systems is appreciably affected by the scattering and absorption of electromagnetic radiation by aerosol particles. The prediction of the aerosol extinction depends on the accuracy of the aerosol size distribution model. The model that is most frequently used for the prediction of aerosol concentrations and the effect of aerosols on extinction in the marine atmosphere is the US Navy Aerosol Model (NAM) ${ }^{1}$. Although the NAM predictions show a good agreement with aerosol concentration measured in open ocean, ${ }^{2}$ experimental evidence shows that the reliability of NAM is significantly reduced in coastal areas. ${ }^{3.7}$

The difficulties of modeling the aerosol concentration in the coastal zone are confirmed by the analysis of data collected on the island Inisheer (Aran Islands. Ireland) west of Galway Bay on the North Atlantic coast. As an example. Figure 1 shows a

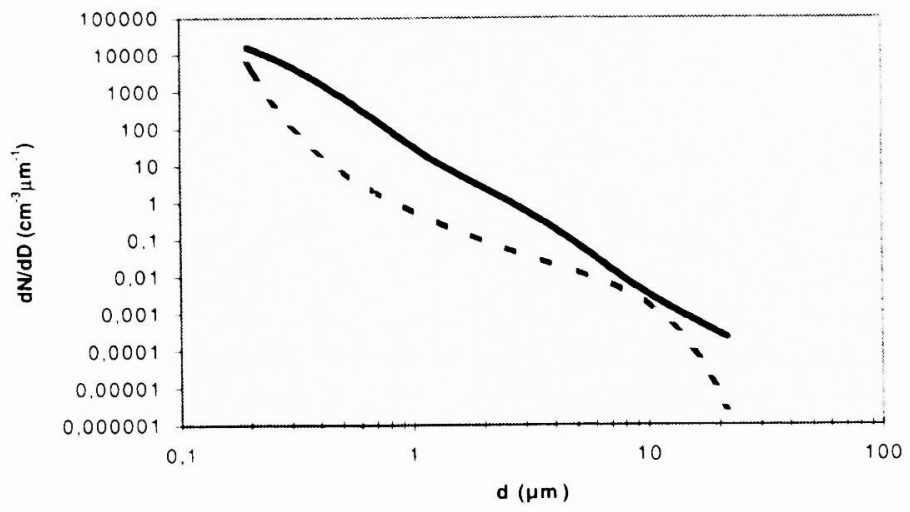

Figure. 1: Comparison between the average size distribution measured on the island Inisheer at $10 \mathrm{~km}$ fetch for a wind speed of $10 \mathrm{~m} / \mathrm{s}$ (dashed line) and the calculated distribution using NAM (solid line) with an air mass parameter of 7 .

Further author information:

LEPI. BP 132, F-83957 La Garde, France. Telephone: +3349414 2446, Fax: +3349414 2572. Email:

piazzola@isitv.univ-tln.fr.

TNO-FEL, P.O. Box 96864, 2509 JG The Hague, The Netherlands. Telephone: $+31703740451 / 0462$, Fax: +31 70 374

0654,Email: amjn1@fel.tno.nl or deleeuw@fel.tno.nl. 
comparison between the average aerosol size distribution measured at a wind speed of $10 \mathrm{~m} / \mathrm{s}$ and $10 \mathrm{~km}$ fetch and the calculated aerosol spectrum using NAM.

In this contribution, an analysis is presented of the Inisheer data set showing the influence of fetch on the aerosol size distributions. The fetch dependence is subsequently parameterized as an extension of the NAM equations and replaces the air mass parameter in the model. This is an alternative approach to include the coastal effects in a model for the optical properties of the marine atmosphere. As in the original model, the input consists of readily available meteorological data, which facilitates the use of the model in operational conditions.

\section{FIELD SITE AND INSTRUMENTATION}

Particle size distributions and meteorological parameters were measured on the island Inisheer, situated off the west coast of Ireland $\left(10^{\circ} 35^{\circ}, 53^{\circ} 27^{\prime}\right.$, see figure 2) during two periods of 4 weeks each in September 1994 and August/September 1995. The aerosol counters and meteorological sensors were located at $30 \mathrm{~m}$ height on the light house at the south tip of the island. Size distributions in the 0.1-21 $\mu \mathrm{m}$ radius range were obtained using two Particle Measuring Systems classical scattering spectrometers: a CSASP-200 and a CSASP-100HV. The data accumulation period was 1 minute, and the data was stored as the average over a 10-minute interval. Polynomial fits of $1^{\text {st }}$ (Junge) and $5^{\text {th }}$ order in $\log (\mathrm{dN} / \mathrm{dD}$ ) versus log (D) space were made to the distributions to facilitate the analysis. Prior to the experiments, the probes had been calibrated with particles of known sizes.

Figure 2: Area map of the Irish West coast and the island Inisheer (center of wind rose), showing the four wind direction intervals included in the present analysis.

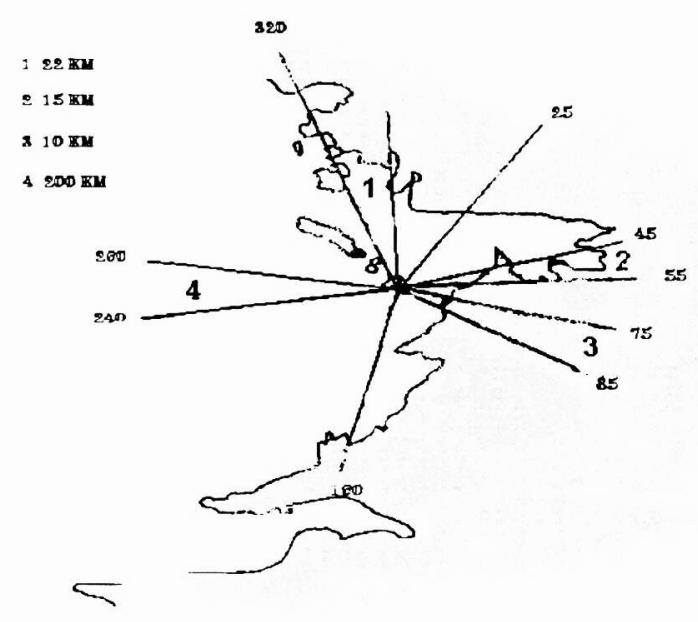

The area map (figure 2) shows that the fetch varies from circa 6 to 30 kilometers for wind directions between $300^{\circ}$ and $160^{\circ}$, whereas the $180^{\circ}-270^{\circ}$ wind direction interval corresponds to open waters (Note that the map in figure 2 is rotated with respect to the North). Since fetch is ill-defined for this direction, we use the equation given by $\mathrm{Hsu}^{8}$ to determine an upper limit of the fetch for the $180^{\circ}-270^{\circ}$ interval:

$\frac{g X}{U^{2}}<20300$

In equation (1), $\mathrm{X}$ is the fetch in kilometers. $\mathrm{U}$ the wind speed in $\mathrm{m} / \mathrm{s}$ and $\mathrm{g}$ represents the acceleration of gravity. Using the mean wind speed measured for the $180^{\circ}-270^{\circ}$ wind direction interval, this equation yields a maximum fetch of about $200 \mathrm{~km}$. 


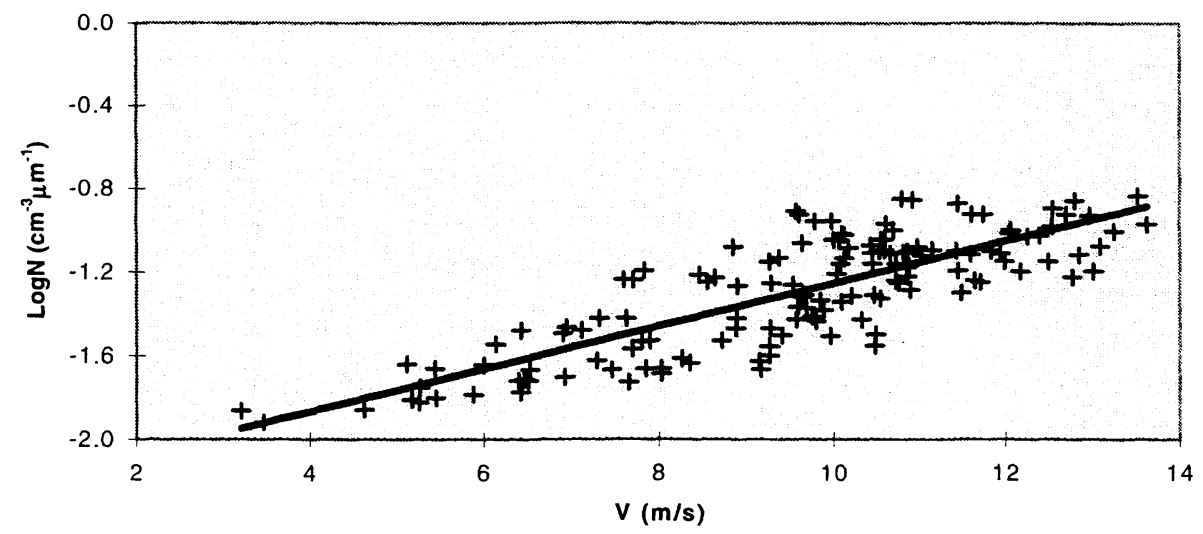

Figure 3 : Concentration/wind speed relation for the $2.5 \mu \mathrm{m}$ particles for $200 \mathrm{~km}$ fetch.

Although this fetch is somewhat arbitrary, the exact value is not very important in this analysis. It was verified that the results of the analysis did not change significantly when a substantially larger fetch was taken.

\section{CONCENTRATION/WIND SPEED DEPENDENCE WITH FETCH}

The analysis was initially focused on particles of $2.5 \mu \mathrm{m}$ radius. This radius was chosen because these particles are predominantly of marine origin ${ }^{5,9}$ and are therefore suited as tracers for the influence of fetch on the production of marine aerosol. To determine the effect of fetch on the aerosol concentration, the data was grouped in four wind direction intervals, each corresponding with a particular fetch.

It is well-recognized that the concentration of sea-spray aerosols is primarily a function of wind speed. Often, a simple logarithmic relation between the particle concentration $\mathrm{N}$ and wind speed $\mathrm{U}$ can be obtained: ${ }^{10}$

$\log N=a U+b$

As an example, figure 3 shows a logarithmic-linear plot of the particle concentration versus the wind speed as observed for a fetch of $200 \mathrm{~km}$. Similar plots were made for the other fetches, and the results of the linear regressions of the concentration/wind speed dependence are reported in table 1.

TABLE 1: Slope and intercept of the concentration/wind speed dependence ( $\log N=a U+b)$ for $2.5 \mu \mathrm{m}$ particles for different fetches

\begin{tabular}{lccccc}
\hline $\begin{array}{l}\text { Wind } \\
\text { direction }\end{array}$ & Fetch $(\mathrm{km})$ & Slope & Intercept & Number of samples & $\begin{array}{c}\text { Wind speed } \\
\text { interval }\end{array}$ \\
\hline $75-85$ & 10 & $0.020( \pm 0.009)$ & $-1.98( \pm 0.085)$ & 56 & $5-11$ \\
$45-55$ & 15 & $0.042( \pm 0.017)$ & $-2.08( \pm 0.093)$ & 110 & $2-8$ \\
$320-335$ & 22 & $0.085( \pm 0.011)$ & $-2.15( \pm 0.060)$ & 255 & $4-10$ \\
$240-260$ & 200 & $0.105( \pm 0.006)$ & $-2.31( \pm 0.060)$ & 175 & $1-14$ \\
\hline
\end{tabular}


Each fetch in table 1 strictly corresponds to a rather small interval of wind directions to be representative of a precise fetch length. The data used in each of the concentration/wind speed plots spans various days of the experiment and a range of wind speed values, including low wind speed periods. Therefore, we feel that the slope is representative of the wind speed dependence and that the intercept represents the concentration when the wind speed approaches zero. The standard deviation for the intercepts for short fetches is larger than for longer fetches. This may be indicative of local sources ashore for which the source strength varies in time. A similar behavior has been observed in the Mediterranean coastal zone. ${ }^{11}$

A comparison of the individual slopes in table 1 shows that the increase in slope between the 15 and $22 \mathrm{~km}$ fetch seems rather large in view of the $7 \mathrm{~km}$ increase in fetch. A possible explanation may be that the air mass arriving from the $320^{\circ}$ $335^{\circ}$ wind direction has actually traveled a longer distance over water than $22 \mathrm{~km}$ due to air masses arriving from the remote North Atlantic taking a more Southerly course following the coast. In the absence of air mass trajectories, this cannot be verified.

The main result of the present analysis is that the concentration/wind speed relation shows a monotonous variation of the slope and the intercept with fetch, as evidenced by table 1 . However, the dependencies of slope and intercept on fetch are opposite. The slope increases with fetch, whereas the intercept decreases. This behavior of the slope and the intercept is consistent with the mixed origin of the particles in coastal areas. ${ }^{5.7}$ The production mechanisms of sea-spray particles become more effective at higher wind speeds, resulting in larger concentrations over water. On the other hand, the overwater concentration of land-originated particles decreases at higher wind speeds due to dilution by faster dispersion ${ }^{12}$ and enhanced turbulent deposition. The actual behavior of the aerosol concentration as function of wind speed results from the relative contribution of marine- and land-originated aerosols. For larger fetches, the marine-originated particles prevail resulting in larger slopes of the concentration/wind speed plots. For shorter fetches, the land-originated particles prevail resulting in larger concentrations at low wind speeds and hence, larger intercepts of the concentration/wind speed plots.

Figure 4 shows the four regression lines for the four fetches. The figure shows that for a given wind speed larger than about $5 \mathrm{~m} / \mathrm{s}$, the concentration of $2.5 \mu \mathrm{m}$ particles increases with fetch. The lower limit of $5 \mathrm{~m} / \mathrm{s}$ wind speed in this behavior suggests a relation with sea surface production mechanisms, since sea surface production only comes into play for wind speeds exceeding 3-4 m/s. It has been suggested that a longer fetch induces a larger whitecap fraction as well as a larger whitecap coverage, ${ }^{7,13,14}$ which would explain the larger concentrations of aerosol for the larger fetches.

It is instructive to compare the concentration/wind speed relations of the present analysis to others reported in literature. To this end, we have selected three experiments which took place on a platform in the North Sea, ${ }^{5}$ a coastal site in the Outer Hebrides, ${ }^{15}$ and a weather ship in the remote North Atlantic. ${ }^{16}$ Table 2 shows the slopes of the concentration/wind speed

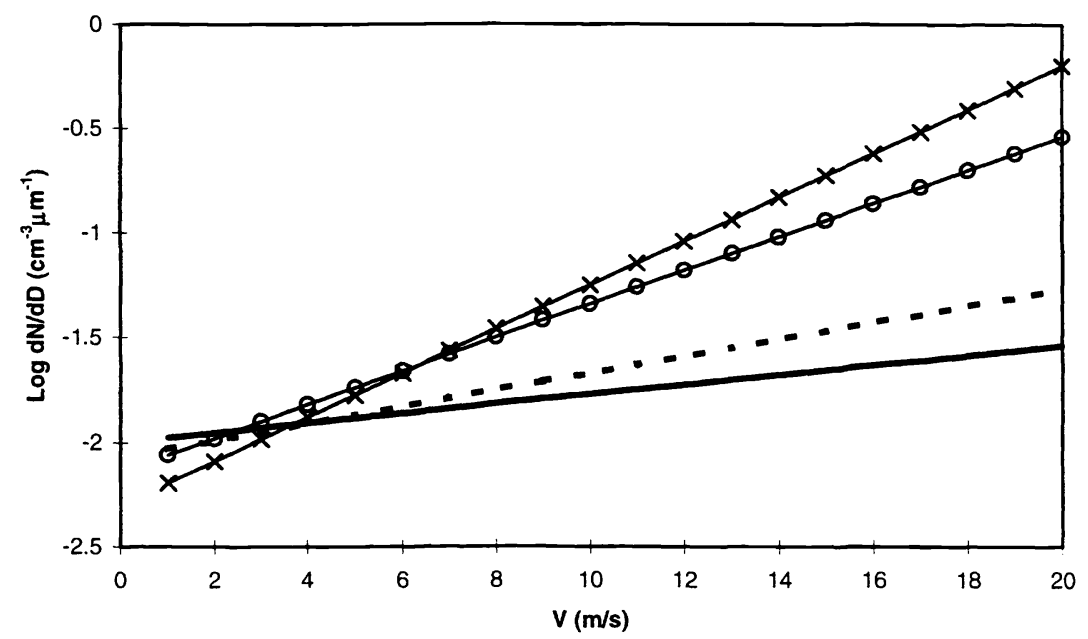

Figure 4: Regression lines of the $2.5 \mu \mathrm{m}$ aerosol wind speed dependence for various fetches: crosses $=200 \mathrm{~km}$ fetch; circles $=22 \mathrm{~km}$ fetch; dashed line $=15 \mathrm{~km}$ fetch; solid line $=10 \mathrm{~km}$ fetch. 
TABLE 2: Slope of the concentration/wind speed dependence ( $\log \mathrm{N}=\mathrm{aU}+\mathrm{b})$

for $2.5 \mu \mathrm{m}$ particles for marine wind directions at various locations

\begin{tabular}{lcc} 
Location & Slope & Wind speed interval \\
\hline Outer Hebrides & 0.045 & $6-30$ \\
North Sea & 0.070 & $2-22$ \\
North Atlantic & 0.090 & $1-15$ \\
Inisheer & 0.100 & $1-14$ \\
\hline
\end{tabular}

regressions for $2.5 \mu \mathrm{m}$ particles found for these data sets, as well as the range of wind speeds encountered during the trials. Only data from marine wind directions has been included to minimize the influence of continental aerosol.

The entries in table 2 have been placed in order of increasing slope. Interestingly, the largest slope is not observed for the North Atlantic trial, which was performed under true open ocean conditions. However, it seems that there is a correlation between the slope and the range of wind speeds encountered during the experiments, i.e., the larger the interval, the lower the slope. This could indicate that the simple logarithmic relation is not valid over an appreciable range of wind speeds. Data presented by Smith et.al. ${ }^{15}$ shows that the slope of the concentration/wind speed plot tends to decrease for higher wind speeds. Consequently, the regression line of a concentration/wind speed plot that extends to high wind speeds (e.g., the Outer Hebrides data set) yields a smaller slope than a regression to a data set that extends only to moderate wind speeds (e.g., the North Atlantic data set).

Also other factors may play a role. Seasonal variations of the sea surface temperature have an effect on the whitecaps and/or bubble distributions from which aerosols are produced. ${ }^{17,18}$ In addition, the intensity of biological activity varies according to season $^{19}$. In particular, the Inisheer data have been measured in August and September during the phytoplanktonic bloom (as observed during the experiment ${ }^{20}$ ), which leads to an increase of gas dissolved in the sea that could in turn enhance the particle production. $^{21}$

\section{THE NAM MODEL EXTENDED TO COASTAL AREAS}

The Inisheer data show clearly the influence of fetch on the aerosol concentrations and illustrate the need of models adapted to the coastal zone. On the basis of the present analysis, a modification of the NAM model is proposed. As in the original model, the aerosol concentration $\mathrm{N}(\mathrm{r})$ is calculated as the sum of three lognormal functions:

$$
N(r)=\sum_{i=1}^{3} \frac{A_{i}}{f} \exp \left(-C_{i}\left(\ln \left(r / f r_{o i}\right)\right)^{2}\right)
$$

where $r_{01}=0.03 \mu \mathrm{m}, r_{02}=0.24 \mu \mathrm{m}$ and $r_{03}=2 \mu \mathrm{m}, f$ represents the humidity growth factor, ${ }^{22} A_{i}$ denotes the mode amplitude and $\mathrm{C}_{\mathrm{i}}$ is the mode width (see below).

The mode amplitudes and widths have been modified to include the fetch as a parameter. In the original NAM model for open ocean ${ }^{1}$ the width parameters $C_{i}$ were all fixed to a value of 1.0. However, Piazzola ${ }^{7}$ found that the aerosol spectrum in the Mediterranean coastal areas was more successfully modeled with varying width parameters. The variable $C_{i}$ allow to better represent the large gradients found in the coastal aerosol spectrum for short fetch, which result from the appreciable concentration of small aerosols of land-origin and the relatively small concentration of large aerosols of marine origin (cf. Refs 5 and 23).

To determine the fetch dependence of mode amplitudes $A_{2}$ and $A_{3}$, concentration/wind speed plots for the four wind direction intervals were made for particles of $0.24 \mu \mathrm{m}$ and $2 \mu \mathrm{m}$ radius. Subsequently, the fetch dependence of the regression parameters (slopes and intercepts of the concentration/wind speed plots) was fitted to an exponential function. The 
exponential dependence was chosen since it results in a strong variation at short fetches and evolves to an asymptotic value for unlimited fetch. This procedure resulted in mode amplitudes as function of wind speed and fetch. Since the experimental aerosol spectrum did not include particles smaller than $0.1 \mu \mathrm{m}$ radius, this method could not be used for the determination of mode amplitude $A_{1}$.

Having obtained the parameterization of mode amplitudes $A_{2}$ and $A_{3}$, amplitude $A_{1}$ and the three widths $C_{i}$ were obtained from a multi-variable fit to the experimental size distributions as function of wind speed and fetch. Obviously, this procedure is somewhat awkward for the first lognormal with a mode radius of $0.03 \mu \mathrm{m}$ since the experimental size distributions only included particles larger than $0.1 \mu \mathrm{m}$ radius. The optimalization of $A_{1}$ and $C_{1}$ had to be based on a rather small overlap of model and experimental size distributions in a radius range where the influence of the second lognormal mode is not negligible.

The fit procedures yielded the following mode amplitudes and mode widths as function of fetch $\mathrm{X}$ (in meters) and wind speed $U($ in $\mathrm{m} / \mathrm{s})$ :

$$
\begin{aligned}
& A_{1}=-26300 \operatorname{Ln} X+317350 \\
& A_{2}=10^{((0.018 \operatorname{Ln} X-0.096) U-0.046 \operatorname{Ln} X+0.6)} \\
& A_{3}=10^{((0.021 \operatorname{Ln} X-0.154) U-0.1 \operatorname{Ln} X-0.74)} \\
& C_{1}=-0.34 \operatorname{Ln} X+5 \\
& C_{2}=-0.09 \operatorname{Ln} X+2.2 \\
& C_{3}=-0.16 \operatorname{Ln} X+4.5
\end{aligned}
$$

In this alternative approach, the fetch replaces the air mass parameter to describe the coastal zone. Contrary to the original NAM where the continental influence was limited to the first lognormal, the new model allows for coastal influence in all three modes. This reflects that the coastal zone not only affects the small aerosol (land-originated particles), but also the large aerosol (sea-spray production).

Due to the difficulties outlined above, the first lognormal with mode radius $0.03 \mu \mathrm{m}$ could only be parameterized as function of fetch. However, experimental data obtained in the Mediterranean coastal zone strongly suggests that the first lognormal depends on other parameters as well. ${ }^{7}$ The wind speed affects the balance between dispersion and removal processes, whereas several complex phenomena such as coagulation, photo-oxidation of Dimethylsulfide (DMS) and new particle formation influence the concentration of the smaller particles.

The second lognormal is parameterized as function of wind speed and fetch, whereas the original NAM used the average wind speed over the last 24 hours. This reflects a fundamental difference between NAM and this alternative approach. The open ocean model NAM considers all aerosol but the smallest to be of marine origin, and uses the average wind speed as a measure for 'aged' marine particles, i.e. particles produced far away that have a relatively long residence time and are still well-mixed throughout the boundary layer. In contrast, the present model stresses the mixed origin of all but the largest aerosols. Because the balance between land- and marine-originated particles can change quickly as a result of changes in wind speed and wind direction, the actual meteorological conditions are more important than the average wind speed.

The third lognormal with mode radius $2 \mu \mathrm{m}$ is also modeled as function of fetch and wind speed to reflect the mixed origin of the particles. The present analysis has shown that the aerosols of $2.5 \mu \mathrm{m}$ radius constitute a mixture of marine- and landoriginated particles. For particles sizes larger than $2.5 \mu \mathrm{m}$, it is expected that the marine-originated particles start to 
dominate completely. This implies that the underlying principles of the third mode are no longer suited to describe that part of the aerosol spectrum and that a new. fourth mode should be introduced to model the large particles of pure marine origin. The need for a fourth mode has already been suggested by De Leeuw as a result of a comparison between NAM predictions and experimental data. ${ }^{6}$ At present, efforts are underway to extend NAM with a fourth mode. The Advanced Navy Aerosol Model (ANAM) is being developed as the successor of NAM for the description of the aerosol concentrations below deck level. ${ }^{24}$ Due to the relative abundance of very large aerosols close to the surface, the inclusion of a fourth mode is essential.

\section{MODEL PERFORMANCE}

Figure 5 a shows examples of aerosol size distributions measured on the island Inisheer at a wind speed of $10 \mathrm{~m} / \mathrm{s}$ but for three different fetches: 10,22 and $200 \mathrm{~km}$. The three curves reflect the mixed origin of the aerosol in the coastal zone: the continental aerosol present for short fetch conditions (high concentrations of smaller aerosol) is replaced by marine aerosol as the fetch increases (high concentrations of larger aerosol). Figure $5 b$ shows that the model predictions for the same conditions resemble the experimental curves and have the same general behavior with respect to fetch.

Figure 6 shows a comparison between model and experimental size distributions for two cases: a short fetch (left) and a long fetch (right). The modeled distributions are in good agreement with the experimental data. To quantify the performance of
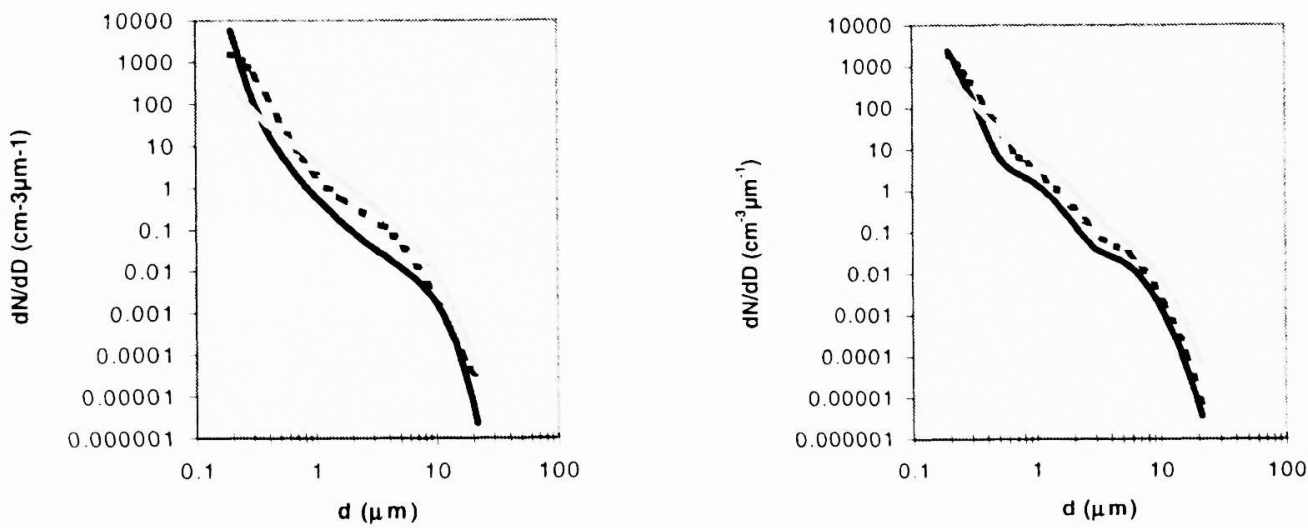

Figure 5: Measured particle size distributions (figure 5a, left) and model predictions (figure $5 \mathrm{~b}$, right). Solid line: $10 \mathrm{~km}$ fetch; dashed line: $22 \mathrm{~km}$ fetch; gray line: $200 \mathrm{~km}$ fetch. The wind speed is $10 \mathrm{~m} / \mathrm{s}$ for all cases.
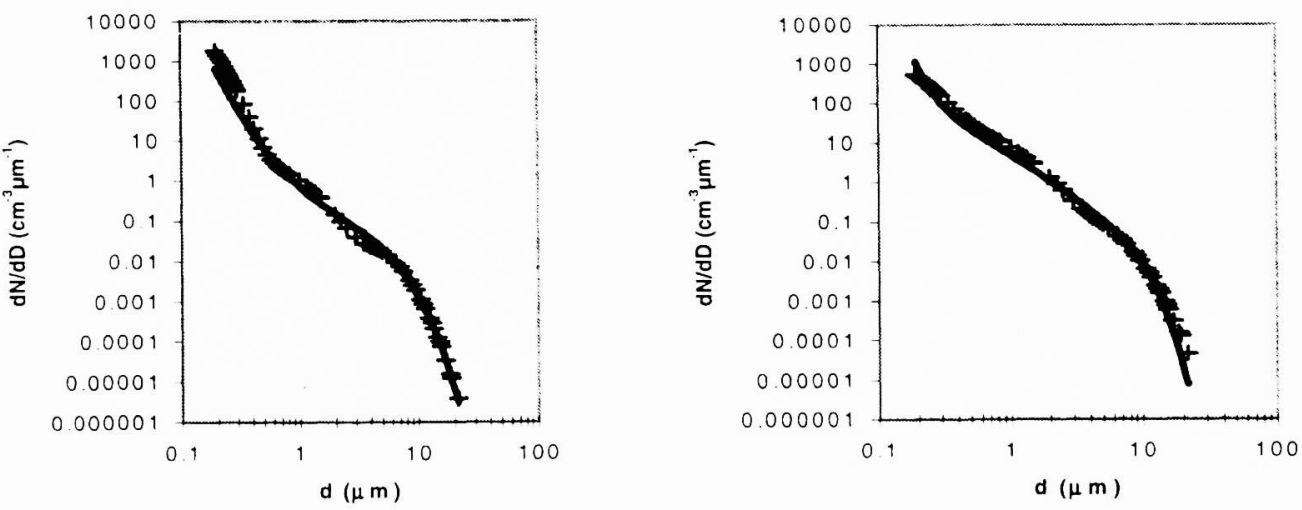

Figure 6: Comparison of measured particle size distribution (solid line) and model (+). Figure $6 \mathrm{a}($ left): fetch $=15 \mathrm{~km}$, wind speed $=7 \mathrm{~m} / \mathrm{s} ;$ Figure $6 \mathrm{~b}($ right $):$ fetch $=200 \mathrm{~km}$, wind speed $=10 \mathrm{~m} / \mathrm{s}$. 


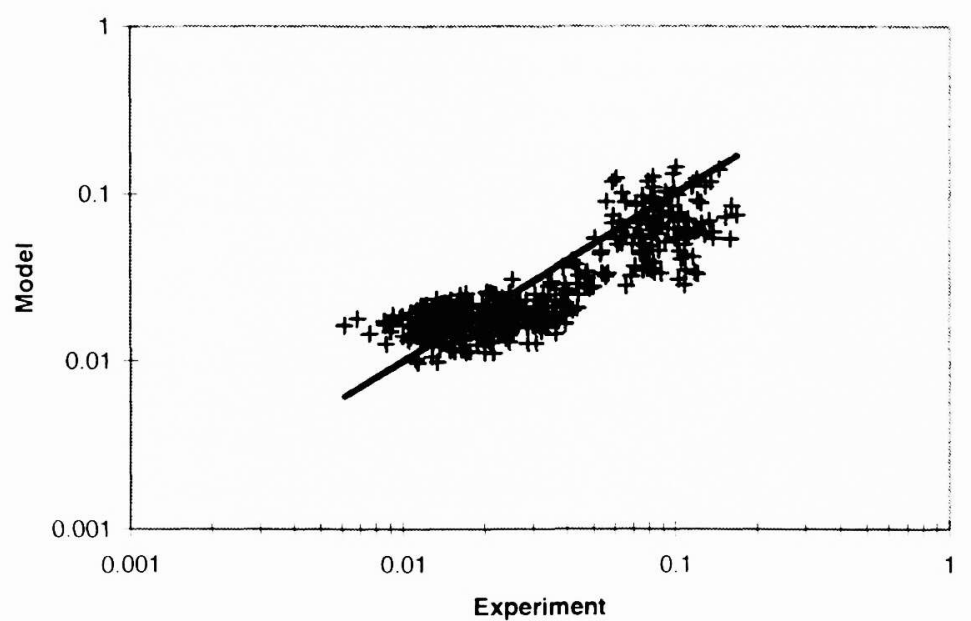

Figure 7: Model performance for the 2.5 $\mu \mathrm{m}$ radius particles. The measured concentration is on the horizontal axis, the model result is on the vertical axis. The solid line denotes ideal model performance.

the model, a scatter plot (Figure 7) was constructed of the experimental and modeled concentrations of $2.5 \mu \mathrm{m}$ particles. This plot includes all available data from the four wind direction intervals. The line $y=x$ in the plot represents ideal model performance and the standard deviation of the data points with respect to that line can be taken as a measure for the performance of our model. ${ }^{4.5}$ The standard deviation amounts to 0.19 . which means that the model predicts the concentration of $2.5 \mu \mathrm{m}$ particles to within a factor of 1.6 (68\% confidence limit). The model performance is reduced for the smallest aerosols (radius $<0.2 \mu \mathrm{m}$ ), because the parameterization of the amplitude and width of the first lognormal mode (radius 0.03 $\mu \mathrm{m}$ ) hampered from the lower limit of the experimental size distribution (cf. previous section).

Finally, it is necessary to address the transition from coastal zone to open ocean. The present extension of NAM is intended for use in coastal areas where fetch is important. For unlimited fetch, however, the extension should evolve into the original NAM model which has proven its value in open ocean conditions. Mathematically, such a gradual evolution of the coastal model into NAM is not possible, because the present model uses different parameters (fetch, wind speed, relative humidity) to predict the aerosol concentration than the original NAM model (air mass parameter, wind speed, average wind speed, relative humidity).

Figure 8 shows an example of the experimental size distribution for a fetch of $200 \mathrm{~km}$, and the spectra predicted by NAM and the coastal model. The three curves are very close, which indicates that both NAM and the coastal model correctly predict the aerosol spectrum at a fetch of $200 \mathrm{~km}$. This allows to switch between the two models at this fetch length. It is therefore suggested that the coastal model is used for fetches up to $200 \mathrm{~km}$, whereas NAM should be used for longer fetches.

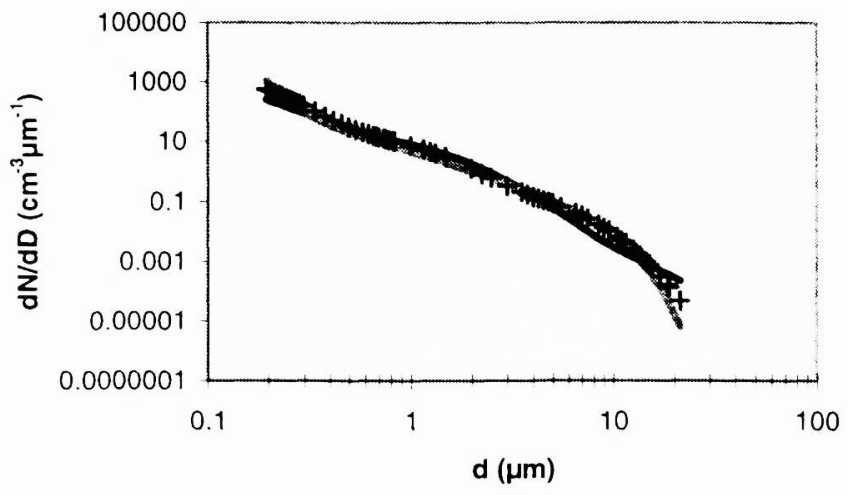

Figure 8: Comparison of a measured size distribution (solid line) and the predictions by NAM (gray line) and the coastal model $(+)$. 


\section{CONCLUSION}

On the basis of a data set obtained on the island Inisheer (Irish West Coast) an empirical aerosol model for the coastal zone has been developed. The model is formulated as an extension of the Navy Aerosol Model, and uses fetch instead of the air mass parameter to account for the contribution of continental aerosols. Over the whole range of fetches encountered in the data set, the coastal model predicts the measured aerosol spectrum with an accuracy better than a factor of 2.0 . The use of the coastal model is recommended for fetches shorter than $200 \mathrm{~km}$. Above this limit, the aerosol spectrum is successfully described by the original NAM model.

The coastal model was developed on a single data set, representative for the Irish West coast. Some of the characteristics of the data set have also been observed for other geographical regions such as the North Sea and the Mediterranean, but differences have also been found. It is necessary to extend this work to other data sets to determine whether the present model can be more generally applied. It is hoped that these continued efforts lead to a general NAM model for the coastal zone.

\section{ACKNOWLEDGMENTS}

This work was supported by the Royal Dutch Navy under contract no. A96KM795. The work was performed while Dr. Piazzola was a visiting scientist at TNO-FEL, supported by grants of the Dutch Defence Organization and the French embassy in the Netherlands. Dr. Piazzola wishes to express his particular gratitude to Mr J. Leloup, Scientific Attaché at the French Embassy in the Netherlands.

\section{REFERENCES}

1. S.G. Gathman, "Optical properties of the marine aerosol as predicted by the Navy aerosol model, "Opt. Eng. 22, pp. 57-62, 1983.

2. J.H. Richter and H.G. Hughes, "Marine atmospheric effects on electro-optical systems performance," Opt. Eng. 30, pp. 1804-1820, 1991.

3. M. Tanguy, H. Bonhommet, M.L. Autric and P. Vigliano, "Correlation between the aerosol profiles measurements, the meteorological conditions and the atmospheric I.R transmission in a Mediterranean atmosphere," SPIE Proceedings, 1487, pp. 172-184, 1991.

4. A.M.J. van Eijk and G. de Leeuw, "Modeling aerosol extinction in a coastal environment", SPIE Proceedings, 1688, pp. 28-36, 1992.

5. A.M.J. Van Eijk and G. de Leeuw, "Modeling aerosol particle size distributions over the North sea," J. Geophys. Res., 97, pp. 14417-14429, 1992.

6. G. de Leeuw, "Aerosol effects on electro-optical propagation over sea”, SPIE Proceedings, 1971, pp. 2-15, 1993.

7. J. Piazzola, "Etude de la distribution verticale des particules d'aérosols au voisinage de l'interface mer-air en zone côtière Méditerranéenne," Ph.D. Thesis, University of Toulon-Var, France, 1996.

8. S.A. Hsu, "A mechanism for the increase of wind stress (drag) coefficient with wind speed over water surfaces: a parametric model", J. Phys. Oceanography, 16, pp. 144- 150, 1986.

9. A.M.J. van Eijk, F.H. Bastin, F.P. Neele, G. de Leeuw and J. Injuk, "Characterisation of atmospheric properties during MAPTIP", AGARD Conference Proceedings, 567, pp. 19-1 to 19-8, 1995.

10. H.J. Exton, J. Latham, P.M. Park, S.J. Perry, and M.H. Smith, "The production and dispersal of marine aerosol," Quart. J. R. met. Soc., 111, pp. 817-837, 1985.

11. J. Piazzola and S. Despiau, "Contribution of marine aerosols in the particle size distributions observed in Mediterranean coastal zone," Atmospheric Environment, 31, pp. 2991-3009, 1997.

12. S.A. Slinn and W.G.N. Slinn, "Predictions for particle deposition on natural waters", Atmospheric Environment, 14, pp. 1013-1016, 1980.

13. D.B. Ross and G.M. Cardone, "Observations of oceanic whitecaps and their relation to remote measurements of surface wind speed," J. Geophys. Res., 79, pp. 444, 1974.

14. E.C. Monahan and C.F. Monahan, "The influence of fetch on whitecap coverage as deduced from the Alte Weser light station observer's log" in: Oceanic Whitecaps and Their Role in Air-Sea Exchange Processes, E.C. Monahan and G. McNiocaill (eds), Reidel, Noerwell, Mass, USA, 1986. 
15. M.H. Smith, I.E. Consterdine, and P.M. Park, "Atmospheric loadings of marine aerosol during a Hebridean cyclone," Q.J.R. Meteorol. Soc., 115, pp. 383-395, 1989.

16. G. de Leeuw, A.M.J. van Eijk and G.R. Noordhuis. "Modeling aerosols and extinction in the marine atmospheric boundary layer." Proceedings SPIE, 1968, 70-80, 1993.

17. P.A. Bowyer, D.K. Woolf and E.C. Monahan, "Temperature dependence of the charge and aerosol production associated with breaking wave in a whitecap simulation tank," J. Geophys. Res., 95, pp. 5313-5319, 1990.

18. A.L. Walsh and P.J. Mulhearn, "Photographic measurements of bubble populations from breaking wind waves at sea," J. Geophys. Res., 92, pp. 14,553-14,565, 1987.

19. S.A. Thorpe, P. Bowyer and D.K. Woolf, "Some factors affecting the size distributions of oceanic bubbles," J. Phys. Oceanography, 22, pp. 382-389, 1992.

20. P. Bowyer, D.K. Woolf and G. de Leeuw, "The investigation of the influence of bubbles on air-sea interaction", MAS2 CT930056, Final report to the European Community.

21. M. Stramska, R. Marks and E.C. Monahan, "Bubble mediated aerosol production as a consequence of wave breaking in supersaturated (hyperoxic) sea water," J. Geophys. Res., 95, pp. 18,281-18,288, 1990.

22. H.E. Gerber, "Relative humidity parameterization of the Navy Aerosol Model (NAM), NRL Report, 8956, National Research Laboratory, Washington DC, USA, 1985.

23. C. O'Dowd and M.H. Smith, "Physicochemical properties of aerosols of the northeast Atlantic: evidence for wind-speed related submicron sea-salt production," J. Geophys. Res., 98, No. D1, 1137-1149, 1993.

24. S.G. Gathman and A.M.J. van Eijk (1998). Characterizing large aerosols at the lowest levels of the marine atmosphere. Propagation and imaging through the atmosphere II, L.R. Bissonnette and C. Dainty (eds). SPIE conference 3433, 19-24 July, San Diego, CA, USA. 